\title{
Aerospace Electric Generator Specification and Selection - Opportunities and Challenges
}

\author{
Avo Reinap \\ Div. Industrial Electrical Engineering and Automation, Lund University, Lund, Sweden \\ E-mail: avo.reinap@iea.lth.se
}

\begin{abstract}
The goal of this work is to specify and investigate suitability of a number of selected permanent magnet synchronous machine (PMSM) topologies to be mounted directly on a low pressure shaft (LPS) of a geared turbofan engine. The starting point of the work is to explore the status of electrical machines for more electric engine in order to study different design aspects when identifying and defining the designs. Even though the high flexibility and power density is anticipated from the system electrification the reliability is one of the most important aspects for the machine topology development and faultlessness can compromise desired performance. Large inner diameter of LPS and wide speed range are challenging the selection and specification of PMSM. The design initialisation is carried out by looking for more fault tolerant arrangements between machine windings and power converter topologies and appropriate rotor layouts that can provide excitation and constructional stability. Design space exploration is carried out on surface mounted Halbach array PMSM with distributed winding in the stator as one of the machine types that is best suited for high power density and high-speed application. Machine design aspects on modular design for faultlessness and cooling integration for enhanced thermal management and higher power density are the arguments behind the sensitivity study carried out on interior permanent magnet synchronous machine with nonoverlapping concentrated winding. Six different magnetic core materials are compared to demonstrate that thin FeSi electromagnetic steel grades improve efficiency and FeCo materials mainly torque density but the machine may remain unsatisfactory in power and efficiency.
\end{abstract}

Keywords: More electric engine, electric generators for aircraft engine, electric drive and electric power system, permanent magnet synchronous machines, design of electrical machines, inset permanent magnet and Halbach array rotors, power losses in magnetic cores, cooling integration of electrical machines,

\section{Introduction}

Transport electrification gains uninterruptedly interest as this is apparently one of the promising ways towards more sustainable, energy efficient and environmentally friendly transportation in the future. All means of transports from road and rail to marine and airborne are under the investigations of the possible benefits that powertrain electrification can provide and accomplish compared to the existing solutions. The anticipated improvement in added functionality, increased efficiency, improved packing and power density is achieved through the advancements in control technology and power engineering which is applied on the electric drive system optimization and coincident development of system components: energy storage, power (micro) grids, power electronic converters and rotating electrical machines. No pain, no gain - all system components, in an electric drive system, are under continuous research and examination in order to increase the functionality, power density, efficiency and reliability. The technology development is inspired by seeking for more suitable materials supported by rational production technologies and thereby looking for more affordable solutions and sustainable products. Since the transportation means motion, mechanical energy needs to be present and unquestionably the electrical machine or machines take place in this system. If the road and rail bound vehicles seek for traction motors, then aircrafts are after electric generators / starter motors that would fulfil the growing demand on electric power and added functionality. This demand is due to the electrification in the aircraft, where many existing hydraulic, pneumatic and mechanic actuators or related functions are replaced by electric counterparts.

The advancement of More Electric Aircrafts (MEA) hangs on the development on More Electric Engines (MEE) where the integration of electrical machines into the gas turbine is 
foreseen and encouraged not because of supplying increased electric loads but as the possibility to reduce weight and increase efficiency of the turbomachinery. Due to harsh operating conditions and increased demand not only on power but also power density concern system developers and component designers accomplishing the challenging task of specifying an appropriate electric power generation and electric power system. As a matter of fact, the increase in power density or load is naturally not coaligned with the increase of durability, reliability or efficiency. In order to meet this challenge, the article explores the opportunities on 1) high efficiency magnetic core materials, and 2) power electronic converter to winding arrangement that are considered in the electrical machine design and development process. This paper addresses the design of electrical machine which is directly attached onto a low-pressure spool (LPS) of a turbofan engine. The design initialization is carried out in the first section where the anticipated perspectives and objectives for MEE [1]-[3] are faced to the recognized challenges and opportunities [4]-[7]. The aim is exploring several design aspects and specifying four generator topologies for further study. The following section explores the design space and compares the candidates in terms of size and material selection for the magnetic core since the large inner diameter of the LPS, the available geometric space and the speed range are some of the early recognized design concerns. The third section focuses on a single topology among four candidates and investigates some compromises between electromagnetic and mechanic and thermal design.

\section{Electrical machine specification}

First the jet-engine generator arrangement is studied, followed by electric drive system topologies with concern on power electronics, converters and microgrids [9]-[14] in order to specify the boundary conditions. Concerning to the performance and faultlessness capability, the converter to machine winding arrangement is explored [15]-[19] and the performance limits of the machine topologies are investigated [21]-[28]. Most commonly an electrical generator in a commercial transport aircraft, which is a three-stage wound-field synchronous machine, is externally coupled to high-pressure spool (HPS). Permanent magnet types of machines, which would provide engine starting function and higher power density, are continuously researched as a technological improvement for MEE.

\subsection{Jet-engine generator arrangement}

In the face of the recent growth in air transport and climate concern the powertrain electrification and weight reduction has been always one of the aircraft development targets. Already back in a half century the advantages on integrated engine-generator concepts were drawn and suitable electrical machine designs not only compared but also suggested [1]. The work concluded that 1) electrical machine should be mounted to High Pressure Spool or Shaft (HPS) so that the electrical machine (EM) is not only generating electricity but can be used at least 30 seconds to start commercial turbofan engine $180 \mathrm{kN}$ thrust class, 2) the use of electric energy reduces the need of engine shaft driven accessories and bleed air requirements, which improves packing and efficiency of the engine, and 3) the machine requires no extra space than already available and the reliability is higher compared to the machines used at that time. As a matter of fact, the power rating and the inner diameter of the machine, which is $\varnothing 208 \mathrm{~mm}$ and $200 \mathrm{kVA}$, are nearly the same values targeted in this work. Even if full electrification is encouraged [2], which anticipates multispool embedded electrical machines with integrated active bearings in order to facilitate power management and dynamics in the turbomachinery, and technological development would support this growth [3] the published efforts on design and prototyping of embedded EMs and specifically EMs for LPS and for commercial transport aircraft are less common.

The evolution of the electric generation and power system perspective in context of MEA and MEE can be shortly summarized based on a few publications where the system development challenges [4] and some of the achievements [5] are reviewed. An extensive review of an electrical generator development is given in [6] and the generator development perspectives are collected in [7]. As the EM operates not only in generating operation but also motoring when starting up the engine, the engine architecture development gives both opportunities and challenges to electrical machine engineering to contribute to system efficiency, functionality and reliability. The anticipated features are that the electrical machines are attached to multiple engine shafts to provide not only distributed power generation but also enhance engine control at transient operation. According to [5] the distributed power generation endows with lower fuel conception at increased electrical loads meanwhile the wide speed range of the low pressure spool is one of the challenges and research subjects for an MEA paradigm.

The target engine configuration is a geared twin-spool turbofan (Figure 1) where Geared Turbofan Technology enables less fuel burn, acoustic noise and emission [8].

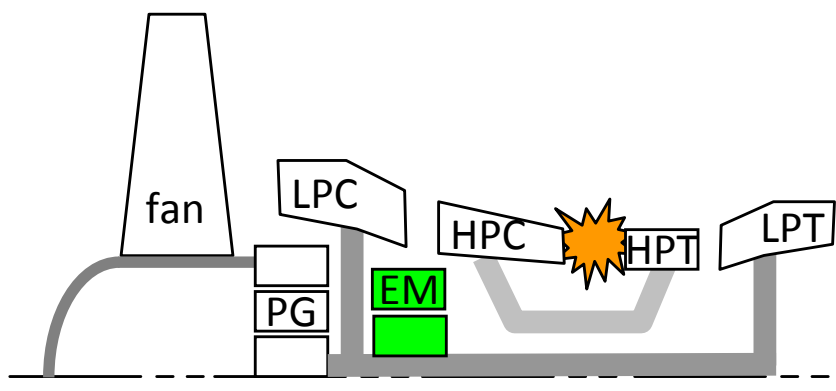

Figure 1 Schematic layout of a geared twin-spool turbofan.

The engine layout shows following components as a fan, planetary gear (PG), low pressure compressor (LPC), high pressure compressor (HPC), combustion chamber, high pressure turbine (HPT), low pressure turbine (LPT) and electrical machine embedded onto the low-pressure spool. Even if the EM for LPS is not able to start the engine it can contribute to the start up. However, the EM needs to operate over a wider speed range EM for HPS. The machine 
operates mainly in generator operation including ram air turbine (RAT) function to generate emergency power at wind milling action of the gas turbine [4].

The design parameters of EM for LPS are selected inexact to the target system in order to pronounce the design challenges rather than integration constrains. The inner diameter of EM is $\varnothing 200 \mathrm{~mm}$ and the constant power speed range is defined from 1500 to $7500 \mathrm{rpm}$ while the over speed is selected $15000 \mathrm{rpm}$ for overload investigations.

The early design concerns of the large diameter and rotation speed is due to conflictive interest of reducing surface speed of the rotor of EM and the number of poles for a largest suitable supplied electric frequency. In case of inner rotor EM, the smaller outer diameter would result smaller structural stress due to centrifugal forces, but it would result unnecessarily high number of poles and magnetization frequency and related power losses or magnetically inefficient EM construction. On the contrary, large rotor would challenge not only the mechanical construction but also requires larger stator core for the best electromagnetic outcome. In either case, the EM may generate already unnecessary amount of no-load losses while operating at noload and if the magnetization cannot be easily reduced, which would be the case of more torque efficient permanent magnet (PM) machines.

A high power-density and efficiency are anticipated from electrical machines. Consequently, PM machines may give advantage due to higher magnetization and electromagnetic torque at limited space. As the power is proportional to the rotation speed the machine becomes smaller and lighter for the given power. As the electrical machine becomes more attractive to provide rather the speed than the torque for given power the presence of mechanical transmission becomes rather practical in order to adapt the load torque and speed requirements. The jet-engine generator arrangement can be compared to the similar electrification development in powertrains for vehicular application, where large low speed direct coupled in-wheel machines can be compared to smaller high speed machines coupled via mechanical transmission (MT). As an outcome, the overall system becomes smaller when optimizing EM torque generation capability to MT torque conditioning capability. As a matter of fact, the most common solution, which is based to B787 and A380 example, the main engine generator is directly coupled to HPS via a gearbox. The advantage of the variable speed shaft (or shafts) driven by HPS as a mechanical power transmission is the effect of challenge segregation as the size of EM is not driven by jetengine and EM is or EMs are by far accessible. Furthermore, the external EM may take advantage of position sensor for more common solution and superior drive performance. In case of embedded EMs sensorless control technique need to be considered. Even if this work focuses on a single large embedded EM for LPS, the presence of PG would give an option of distributed generator system integrated into a set of planet gears. This opportunity, if feasible, would reduce EM size in respect to the rotation speed.

\subsection{Electric drive system}

Concerning to EM, the electric power system (EPS) development moves from the constant input speed and constant output frequency in the EM terminals to variable input speed and variable output frequency in the EM terminals. In case, the magnetization of the EM cannot be changed like in PM machines then also the voltage becomes variable. This can be handled by an active front end rectifier / inverter together with field weakening control. Literally the challenges in mechanical engineering in a constant speed drive (CSD) unit is replaced by new challenges of electrical and control engineering in electric drive system (EDS) to perform safely and provide supply voltage, which is specified for the electric power system (EPS).

The EM coils or/and windings are terminated into a power electronic converter (PEC) (Figure 2). The purpose of the electric drive system (EDS), which consists of EM and PEC, is to connect variable frequency and voltage of the $\mathrm{AC}$ intermediate link to a constant voltage DC distribution system. The purpose of the PEC is to control power flow from EM to EPS. If the excitation of the electrical machine can be controlled like in a conventional three stage fieldwound electrically magnetized synchronous machine (EMSM) then the voltage can be kept constant over the speed and load range as the magnetization current of the main exciter can be adjusted accordingly. This option provides also control over failure modes as the excitation can be switched off in the case of short circuit (SC) current or over voltage at open circuits (OC) of the machine windings. This would not be the case for permanent excitation or permanent magnet synchronous machine (PMSM). In generator and OC operation over voltage is induced at over speed and since the EM cannot be demagnetized it keep short circuit currents circulating at SC. If 3-stage EMPM includes unsophisticated PEC in rotor to control the excitation current, then PMSM must have more sophisticated PEC that can assure desirable faultlessness. A sketch of an EM winding to PEC arrangement is shown in Figure 2. The drawing demonstrates that the entire machine winding is divided into a number of separately driven coils from H-bridges or branches of PEC (upper half in Figure 2) or symmetric winding sections (lower half in Figure 2). The EM winding may have higher number of phases than 3 for the sake of higher redundancy or even efficiency [4].

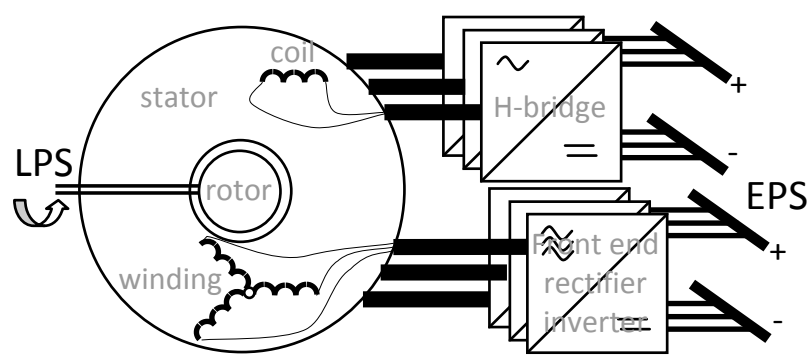

Figure 2 Sketch of electric drive system arrangement.

The electrical machine topology is selected in accordance to winding layout and PEC arrangement so that EDS is capable to provide desirable functionality and reliability. Different EPS architectures and MEA PEC are reviewed in [9] 
whereas [10] compares efficiency and total harmonic distortion (THD) of current in 22 PEC PMSM arrangements, [11] explores deeper into aircraft on-board microgrids including control and distinguishes safety oriented performance optimized research topics between device level and system level as realization oriented and power/energy management related research. As an advantage, high power EM PEC topologies in wind power industry [12] and in DC microgrid arrangement [13] give good insight to aircraft EDS EPS development.

The selection of EM winding layout together with PEC 2level or 3-level inverter topology while targeting higher efficiency, more reliable operation, reduced electromagnetic interference (EMI) results challenging compromises that influences machine design. Depending on reducing weight and power losses a 3-level topologies can be obvious choice while traditional 2-level inverter would offer higher reliability doe to simplicity and component count [14]. A dual fed machine where all phases are supplied independently allows highest grade of fault tolerance capability [10]. Reference [15] explores EMs for MEA load motors and looks into failure probabilities, modular singlephase and multi-channel three-phase approaches to more fault tolerant EDS as a compromise redundancy to added complexity. It is desirable that the system can sustain faults like SC without excessive heat generation or fault propagation and take this into consideration in EM PEC topology selection and arrangement [16]. The modularization of EM coils or winding-sections as well as multi-phase windings provide increased reliability [17]. The EM winding to PEC should be selected so that machine would be able to operate under fault, the occurrence of the fault is minimum, condition monitoring and post fault operation methods can be implemented and applied [18][19]. Furthermore, the practical transport electrification experience in automotive application concerning to EDS realization and reliability gives again good insight to the practical implementation and development [20].

\subsection{Electrical machine types}

From winding layout to converter arrangement and reliability point of view a switched reluctance machine (SRM) is attractive candidate as apart from aforementioned features it has also a high speed and a high temperature capability that because of simple mechanical construction. Likewise, an induction machine (IM) is classed to similar category as this type of machine is used in high speed high power applications. However, this machine, which is also excited via the stator like SRM has not found as common usage in aircraft similar to SRM [6]. This is partly due to the fact that SRM endurance depends on converter and the machine has taken advantage of concentrated windings (CW) while IM uses mostly distributed windings (DW) that have phases in vicinity due to overlapping and this is seen has higher risk for more reliable winding layout. Different machine types: IM, SRM, EMSM, PMSM has been reevaluated time and again shown that the latter, PMSM, has the highest specific torque and power capability per unit of machine while the other machine types are attractive as they have lower cost and can operate over wider speed range [21][22]. Reference [23] organizes various prototypes and commercial products in order to explore suitability of different machine types for jet-engine generator and expresses the reliability concern of PMSM type of machines. The EM development and evaluation are based on appropriate design models [24]. The power density limits and design trends for PMSM are explored in [25] where a fast evaluation model is developed showing that cooling capability has higher influence over power density of EM than rotor surface speed, which is the mechanical design constrain and defines whether the EM is high speed machine or not. Also increasing power levels the power density reduces according to the model. If the previous study compared existing designed prototypes in order to validate the model the maximum surface speed of the rotor was no more than $200 \mathrm{~m} / \mathrm{s}$. Reference [26] explores a number of high speed machines, where the circumferential surface speed $v$ exceeds also $200 \mathrm{~m} / \mathrm{s}$ with the highest value of 280 $\mathrm{m} / \mathrm{s}$ for laminated core rotors and expresses a mechanical limit curve among collected power $P$ (in $k W$ in (1)) from few hundred Watts to few MW with respect to rotation speed $n($ in $1 / s$ in (1)),

$$
\log _{10}(n)=4.27-0.275 \log _{10}(P)
$$

If exploring the design space where the rotation speed $n$ is in the range of 100 to $200 \mathrm{l} / \mathrm{s}$ (6 to $12 \mathrm{krpm}$ ), and the rotor diameter $d$ is in the range of $0.25-0.35 \mathrm{~m}$ then the surface speed $v$,

$$
v=\pi d n / 60,
$$

is in the range of $78.5-220 \mathrm{~m} / \mathrm{s}$. If using the design "guide number" as a combination of speed and power in order to "account" for size and dynamic problems and when selecting $1.5 \cdot 10^{5} \mathrm{rpm} \sqrt{\mathrm{kW}}$ for interior permanent magnet synchronous machine (IPMSM) then the expected power capability for the machine would be ca $150 \mathrm{~kW}$ [22][27].

All EM types can be developed so that they provide higher mechanical or electrical reliability and the focus is more on mechanical stress analysis of the rotor and selecting more suitable winding to converter configurations, respectively [27][28]. This compromises mechanical reliability to electromagnetic performance. In addition, all EM types have been subject to engine generator design initiation and development towards (embedded) EM and EDS prototypes. Concerning to high power $250 \mathrm{~kW}$ machines there are few examples on prototype development and evaluation of: [29][30] RSM and [31][32] PMSM. Most often the prototypes are developed for lower power and higher speed with the intention to connect it externally to HPS via gearbox transmission [33][34][35][36][37][38] when considering the speed and size of the machines. Nevertheless, safety critical machine concepts for direct drive attached to engine main shaft are studied [39] and reduced scale prototype build for evaluation [40]. Likewise, this work proposes a few PMSM topologies for further suitability analysis for usage in LPS in an aircraft geared turbofan engine. 


\subsection{Permanent magnet machines}

A few PMSM topologies are selected for further investigations, where PM rotor and stator with cooling jacket is shown in Figure 3. The initial designs, both outer rotor and inner rotor configurations, are shown so that it could fit into the engine (Figure 1).
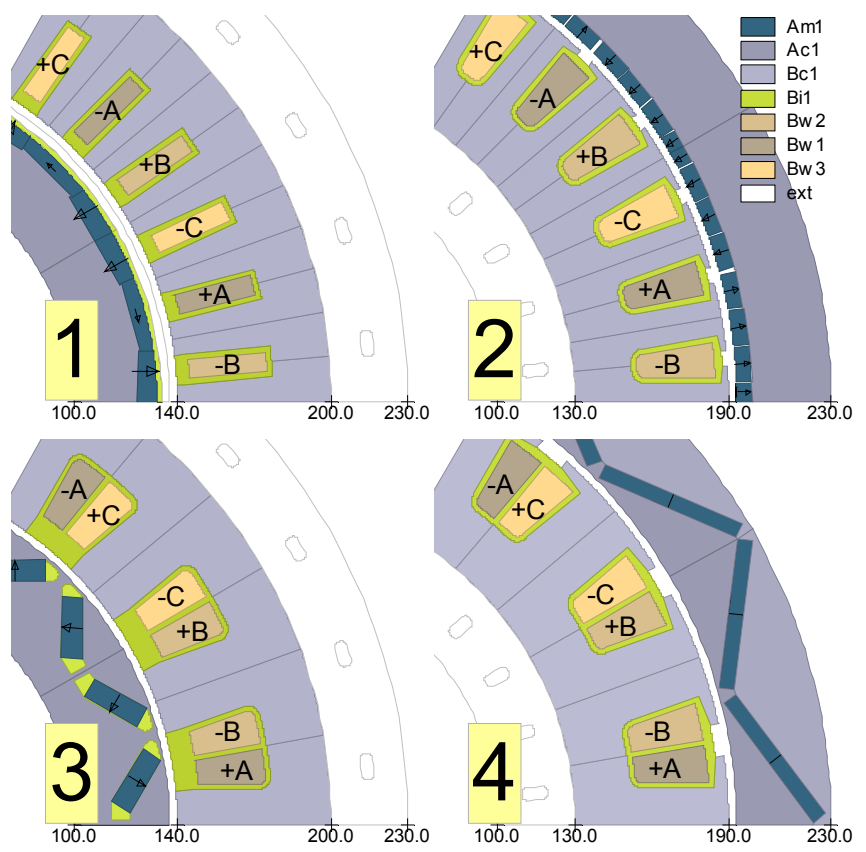

Figure 3 Overview of PMSMs: inner rotor $(1,3)$ and outer rotor $(2,4)$ machines, distributed $(1,2)$ and concentrated winding $(3,4)$ machines, surface mounted $(1,2)$ and interior permanent magnet $(3,4)$ machines.

The PMSM is often preferred due to high efficiency and torque capability. The EM design based evaluation is carried out on inner rotor machines:

- Interior Permanent Magnet (IPM) rotor (3, Figure 3 ) where the mechanical rotor integrity is provided by high strength rotor FeSi steel

- Surface mounted Permanent Magnet (SPM) rotor $(1$, Figure 3$)$ where the mechanical rotor integrity is mainly provided by retaining sleeve

Both these rotors are capable to provide the large constant power speed range that depends on rotor design and the air- gap between rotor and stator. Concerning to stator layout there are two types of winding layouts of interest:

- Distributed windings (1, Figure 3$)$ that has a lower harmonic content but lengthy winding overhangs and end turns,

- Concentrated windings (3, Figure 3) as a more reliable windings due to larger space to neighbour phases

The specified machine configurations have 12-poles and the windings are arranged for 3-phase system (Figure 3) and the end turns are shown in Figure 4 with the exception that the distributed winding has two slots per pole and phase instead of one (Figure 3 ). As there is 2 stator and 2 rotor topologies of interest there is 4 PMSM machines in total under the design development. In addition to the performance estimation provided in this work, the detailed investigation is carried out in [42] while this article focuses on more general aspects on machine topology selection and specification.

Electric machine design consists of two main connected parts: 1) performance estimation and 2) fabrication preparation. Manufacturing aspects are vital in the EM design as the selection of materials and manufacturing aspects have a great impact to the power capability of the machine. As the machine operates at high frequency it is necessary to explore various power loss mechanisms as well as explore possibilities to improve heat dissipation and thermal management. Figure 3 demonstrates two types of windings that can either be premade and placed into the open slots (Figure 31,3 ) or loose coils/group of wires are inserted into semi-closed slots (Figure 3 2,4) that respectively would provide well defined insulation system and thermal contact from winding to core compared to windings with reduced speed dependent losses due to smaller slot leakage apart from strands and transposition. Consequently, the EM topology specification is defined from

- $\quad$ stator side - selecting winding type and assembling technique together with suitable magnetic core, and

- rotor side - specifying magnetization arrangement in respect to speed dependent structural loads and mechanical stresses.

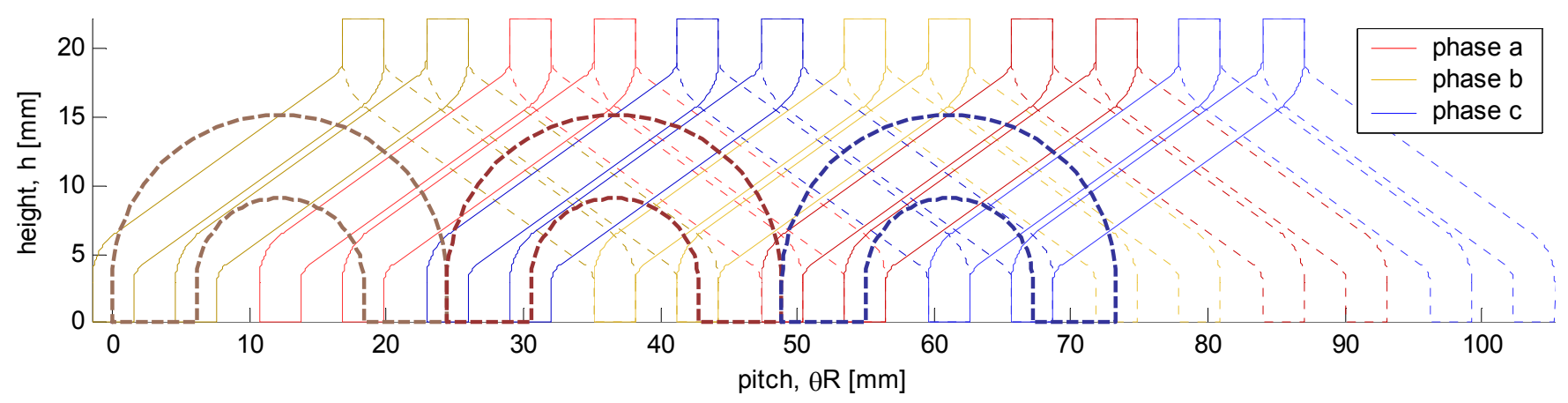

Figure 4 End turn of 12-pole 72-slot diamond type multi-layer winding and 18-slot concentrated type of winding. The coil distribution of the first pole-pair is drawn along inner stator periphery of Ø280 $\mathrm{mm}$ machine. 


\section{Design space exploration}

The machine design consists of number of compromises. The preference is given to electromagnetic design by choosing a narrow $1 \mathrm{~mm}$ air-gap and mechanically weaker rotor design: $2 \mathrm{~mm}$ thick retaining sleeve for SPMSM and $0.5 \mathrm{~mm}$ thick rotor bridges in IPMSM. The purpose of this selection is to identify the PMSM machine topology and selection of core material that suits best for large diameter high speed machine.

\subsection{Parameter specification}

The main EM design parameters exploring the design space is the number of poles, $N p$, and stator radius difference, $\Delta r$, between the outer and inner rotor of the EM. The inner diameter is $280 \mathrm{~mm}$ and the stator core is changed proportionally when increasing the outer diameter from 360 to $440 \mathrm{~mm}$ and number of poles is increased from 8 to 16 (Figure 5).
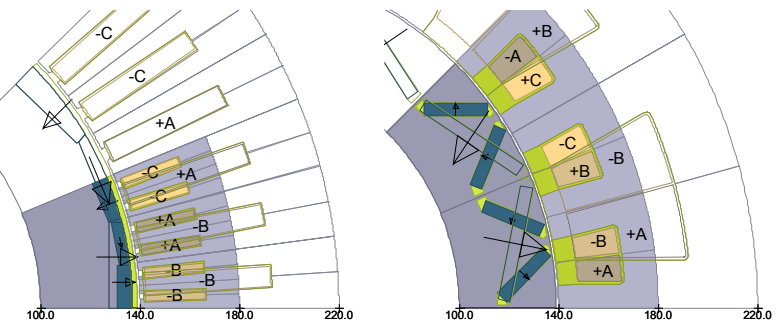

Figure 5 Model variations from small $\Delta r$ and high $\mathrm{Np}$ (filled) to large $\Delta r$ and low $N p$ (unfilled contours).

Intentionally the rotor diameter is kept constant so that EM becomes magnetically limited by an available slot area to produce torque and a size of stator core to carry magnetic flux. Therefore, the machines that would be naturally disregarded due to magnetic saturation would be still choice for high saturation core materials.

\subsection{Material selection}

Concerning to the space and speed requirement the fundamental magnetization frequency becomes high. This is due to fact that the machine has large inner diameter and in order to keep the outer diameter and the weight reasonably low, also avoiding the stator core going into deep saturation, the magnetic pole pitch becomes short, number of poles high and the magnetization frequency high. If considering the nominal operation speed at $7500 \mathrm{rpm}$ and the range of number of poles from 8 to 16 then the electric frequency is changed from $0.5 \mathrm{kHz}$ to $1 \mathrm{kHz}$, which means that high efficiency magnetic core material needs to be chosen for the stator core.

The list of material grades, which are used in design evaluation models, is shown in Table 1 . The first three in the list are cobalt-iron $\mathrm{FeCo}$ materials with higher magnetic saturation capability. The rest of materials are silicon-iron $\mathrm{FeSi}$ materials, where two of them are more suitable for high frequency application due to thinner lamination thickness $[43][44][45][46]$. Since the coating thickness of the electromagnetic steel is unchanged the fill factor is changed.
Table 1 Properties of magnetic core materials

\begin{tabular}{lccc}
\hline Grade & $\begin{array}{c}\text { Density } \\
{\left[\mathrm{g} / \mathrm{cm}^{3}\right]}\end{array}$ & $\begin{array}{l}\text { Thickness } \\
{[\mathrm{mm}]}\end{array}$ & $\begin{array}{c}\text { Core loss } @ 1.5 \mathrm{THz} \\
{[\mathrm{W} / \mathrm{kg}]}\end{array}$ \\
\hline Vacoflux 48 & 8.12 & 0.1 & 38.0 \\
Vacodyr 49 & 8.12 & 0.15 & 100 \\
Vacodur X1 & 7.9 & 0.2 & 146 \\
Arnon-5 & 7.65 & 0.127 & 78.7 \\
HI-LITE NO10 & 7.65 & 0.1 & 83.7 \\
M250-35A & 7.6 & 0.35 & 191 \\
\hline
\end{tabular}

Six different core materials are compared using machine topology 1 in Figure 3. This specific topology has Halbach array magnet arrangement in the rotor and retaining sleeve. The rotor core is defined as laminated material in order to reduce rotor losses and not solid rotor that would be more suitable for high speed operation. The stator has two rectangular slots per pole and phase (Figure 4).

The electromagnetic torque capability as a function of number of poles and stator size is shown in Figure 6. The current density is $10 \mathrm{~A} / \mathrm{mm}^{2}$ and $60 \%$ fill factor is considered of the slot that includes a slot liner, which is the main electric insulation between the winding and the stator core. The torque contours reveal that $\mathrm{FeCo}$ materials have higher torque capability as these materials are less limited of the core saturation

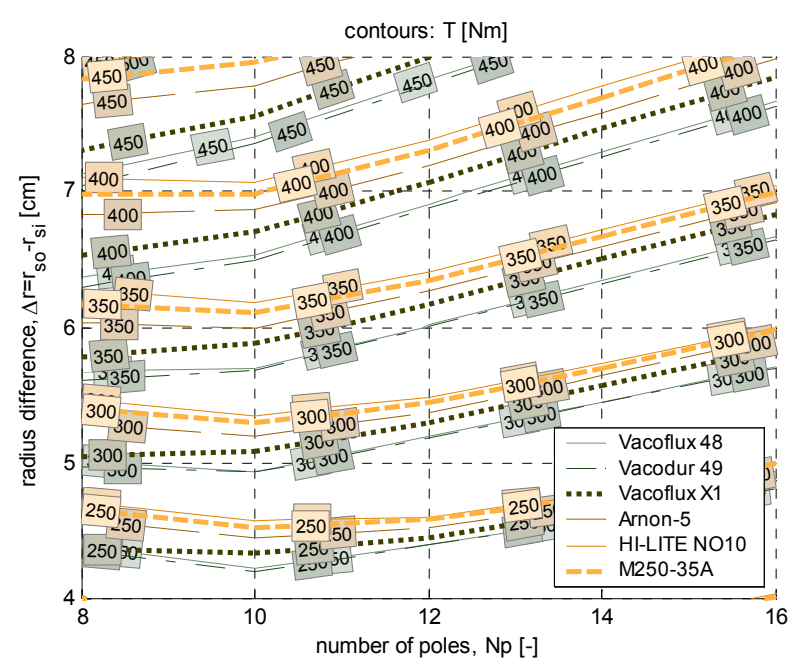

Figure 6 Torque as a function of stator size and number of poles

The high performance material that is capable for higher flux density may not outperform conventional materials as the weight increases [41]. In this comparison, EM designs at low number of poles also EM that have large radius benefit most of replacing the lighter saturated $\mathrm{FeSi}$ core to a weighty $\mathrm{FeCo}$ core. In this analysis the winding layout remains the same and also the stack length is not adjusted in respect to number of poles and stator size in order to simplify the multidimensional comparison. 




Figure 7 Flux density peak value in the stator yoke as a function of stator size and number of poles



Figure 8 Flux density peak value in the stator teeth as a function of stator size and number of poles

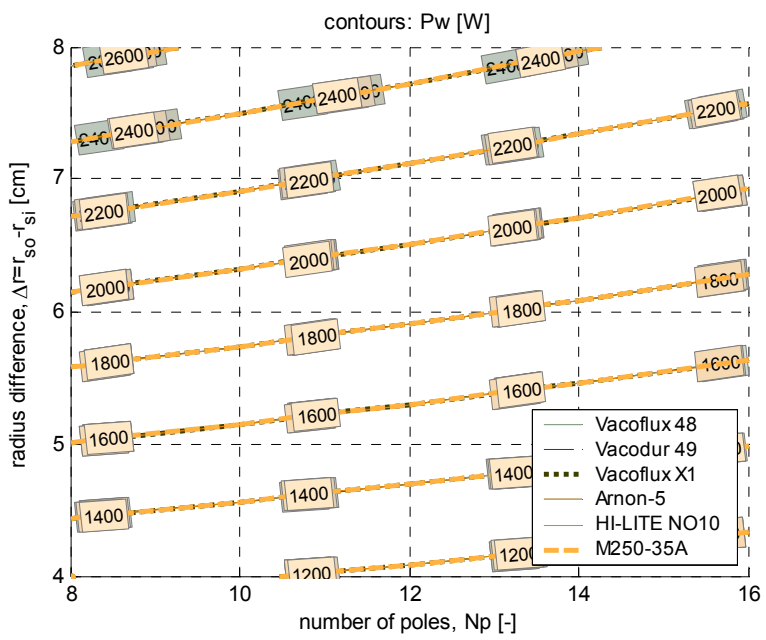

Figure 9 Power losses in the windings excluding AC losses

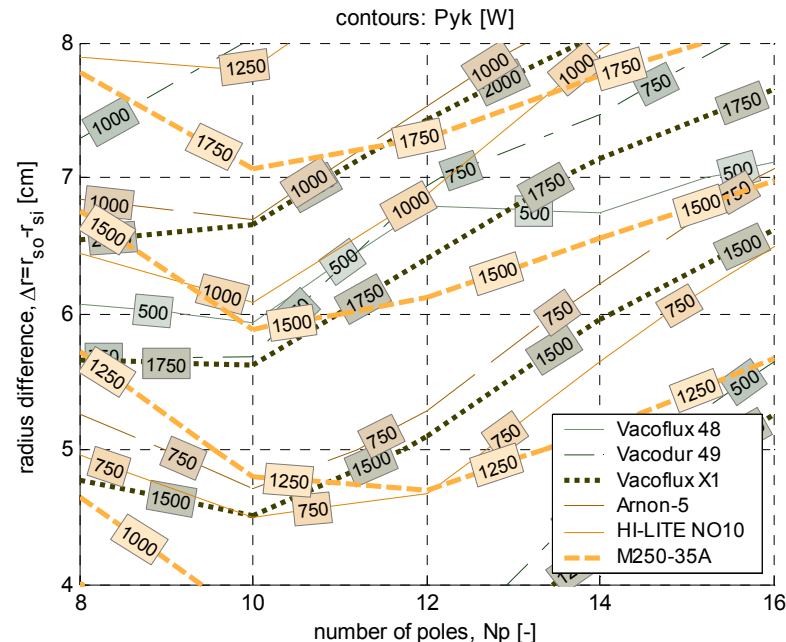

Figure 10 Core losses in the stator yoke as a function of stator size and number of poles

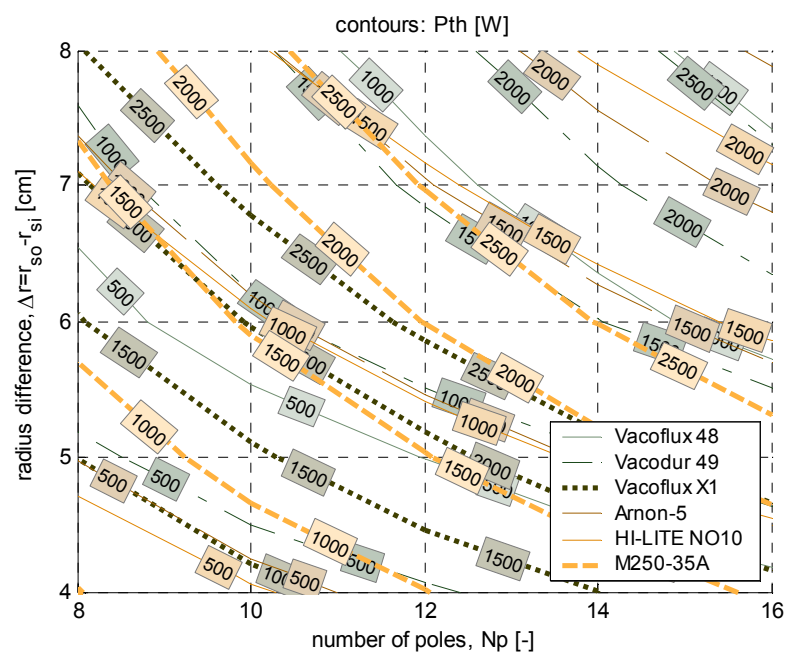

Figure 11 Core losses in the stator teeth as a function of stator size and number of poles

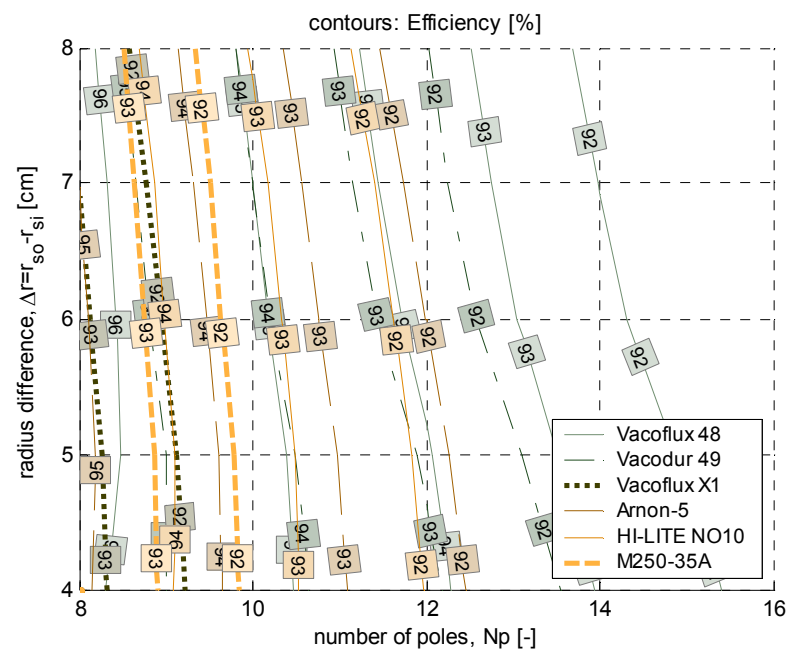

Figure 12 Efficiency as a function of stator size and number of poles 
The peak value of flux density of the loaded machine is shown Figure 7 and Figure 8, where a single representative node in the stator yoke and tooth is shown respectively. The estimated power losses in the stator winding (Figure 9) are in the same magnitude as in the yoke (Figure 10) and stator teeth (Figure 11). Stator teeth may have even higher losses due to high field derivative and harmonic content that is excluded from the power loss estimation as well as the AC losses in the winding. All these figures highlight conventional $0.35 \mathrm{~mm}$ stator lamination $M 350-35 \mathrm{~A}$ and recently developed $\mathrm{FeCo}$ material VacoFlux X1 with compromising material properties and price. As this unsophisticated core loss estimation does not account for stray field power losses the estimated efficiency at $7500 \mathrm{rpm}$ can be even lower than it is shown in Figure 12. However, based to optimistic estimation of power losses and efficiency comparison, the conventional FeSi core material may have even preference over high performance material (Figure 12).

\section{Investigations on design specifications}

The design space comparison is shown for the PMSM type that has a high amount of PM material and a high winding factor that expectedly is able to generate most power for given size compared to other topologies [42]. However, the machine has distributed windings that are not categorised as faultless due to overlaps, even if the machine can provide constant power over wide CPSR it has larger SC and generates more heat in the end turns. Therefore, an IPMSM is investigated that would take advantage of direct cooled windings [47] and have modular concentrated type of winding in order to contribute to fault tolerant operation.

\subsection{Cooling integration}

Conventionally, the EM windings have highest heat losses and highest heat resistance from the conductor to coolant. Therefore, it is appealing to bring dielectric coolant into direct contact to the winding or take advantage of hollow or profiled conductors, but this would cause additional stress and erosion factor on the electric insulation system (EIS).

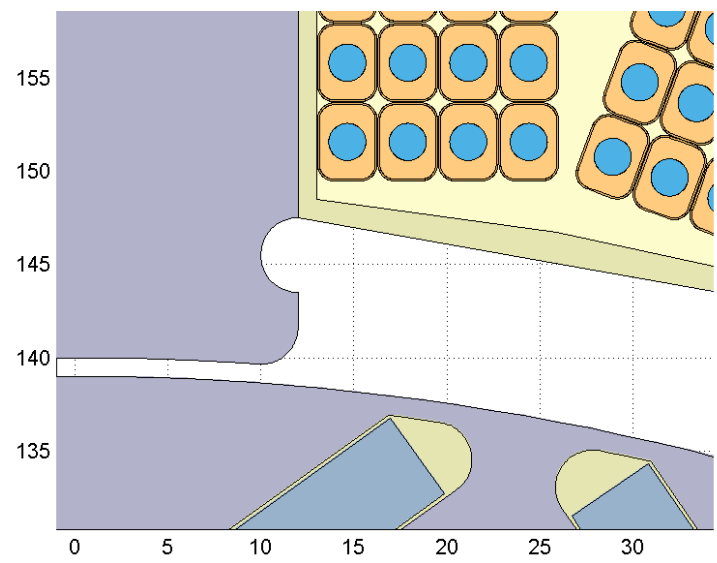

Figure 13 Detail view of IPMSM with direct cooled winding

Cooling integration, which is based on hollow conductors (Figure 13), is studied in [42] where distributed winding with cooling jacket is compared to a concentrated winding machine where the individual coils are connected to corresponding PEC and cooling terminal. Apparently, the concentrated winding machine provides topology with more modular concept that it is easier to produce and assemble; however the serious drawback of this machine is the ripple. Since all the machine types suffer relatively high content of core losses the stator cooling jacket is needed to maintain the desirable core temperature. The direct winding cooling is desirable to provide superior thermal management and higher power capability.

\subsection{Sensitivity study on selected design}

Four different machine topologies are investigated in [42] where CPSR capability is achieved by larger air-gap, which is also needed for a retaining sleeve in the rotor (Figure 31 ) or rotor magnetic saliency (Figure 33 ). The concentrated winding machine (Figure 33 ) have narrower air-gap that contributes to higher efficiency but also considerably higher torque ripple. The electromagnetic performance is challenged by mechanical consideration where initial EM design (D00, Figure 14) is changed either thicker rotor bridges for increased mechanical strength (D01, Figure 14) or larger air-gap (D10, Figure 14), and in both (D11, Figure 14). These changes reduce flux density (Figure 14) and magnetic coupling, as it is seen from the change of .torque capability (Figure 15) and back emf (Figure 16). Even if these changes can reduce torque ripple, total harmonic distortion (in emf Figure 16) and SC current (Figure 17), the power capability of the machine is reduced (Figure 18).

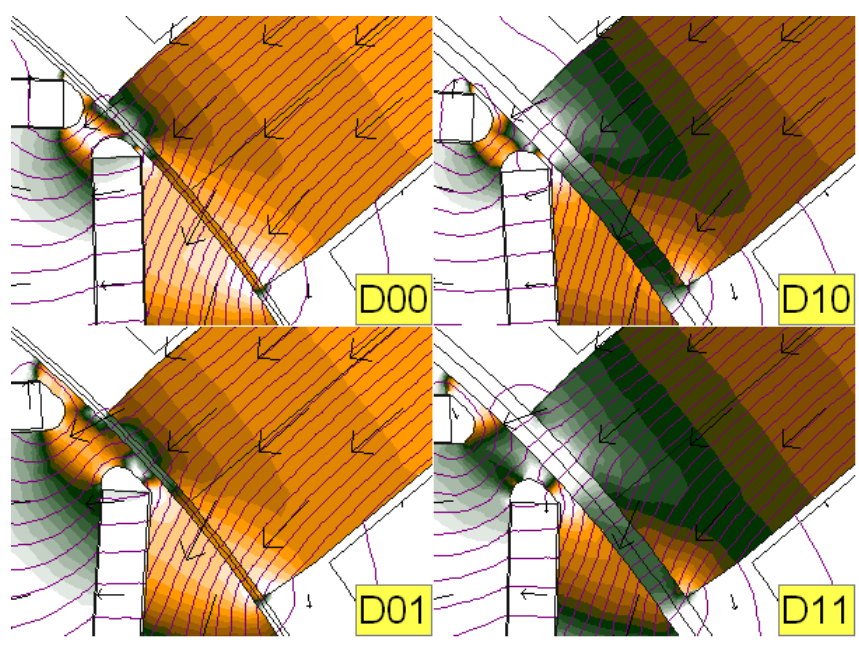

Figure 14 Detailed view of four different machine layouts

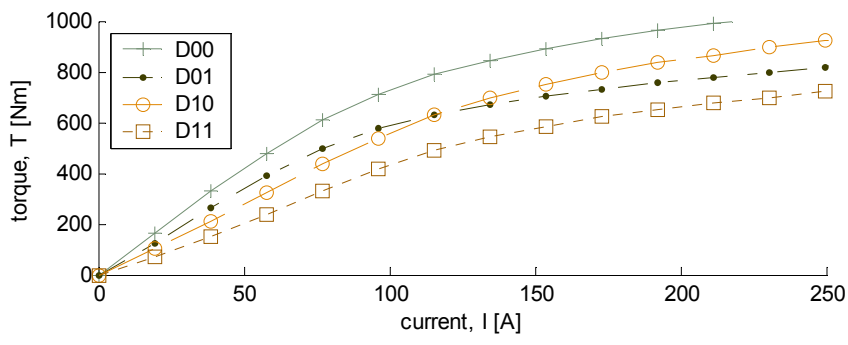

Figure 15 Electromagnetic torque as a function of current 


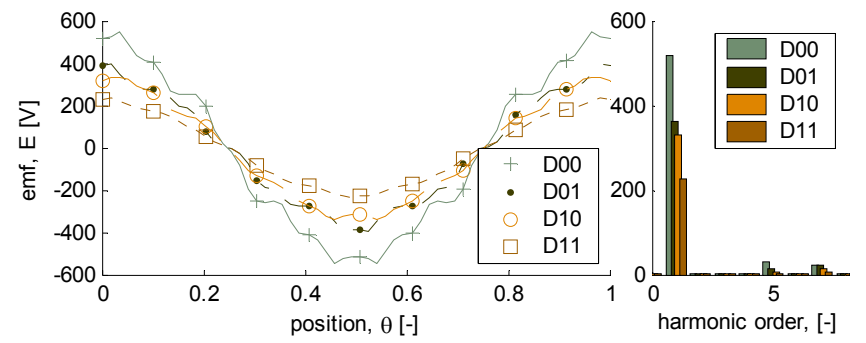

Figure 16 Back EMF waveform and spectrum at $7500 \mathrm{rpm}$

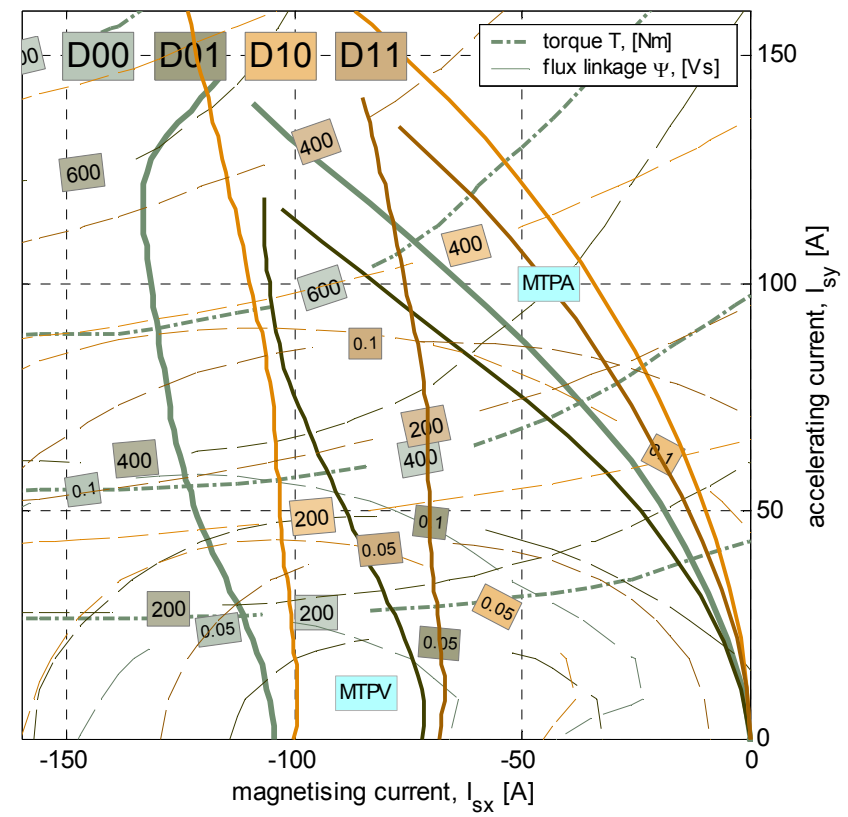

Figure 17 Circle diagram - torque and flux capability as a function of vector current



Figure 18 Torque speed characteristics including highefficiency region above $92 \%$

The machine performance (Figure 18) is estimated based to maximum torque per Ampere (MTPA) and maximum torque per Voltage (MTPV) lines (Figure 17) specified for 28 turn coil at $U d c=300 \mathrm{~V}$, which can be slightly improved by optimizing number of turns to practical dc-link voltage in respect to overvoltage and SC current. The increase in the air-gap reduces not only the magnetization, torque and power but also core losses and moves slightly the high efficiency region towards higher rotation speed. However, the efficiency is relatively low at high speed operation of interest which brings to conclusion that the embedded machine design becomes unnecessarily large and inefficient for high speed operation compared to small geared machine. Nevertheless, this cannot be taken as general conclusion of this limited study provided in this work.

\section{Conclusions}

Electrifying propulsion targets higher system efficiency, weight reduction and all-in-all reduces fuel consumption. Increasing power density for weight reduction means that technology limits need to be pushed further. The ambition of pushing EM design to larger size, higher speed and increased extracted power, results higher structural stress in the rotor due to high rotational speed and in the stator EIS due to electric and thermal loads. More electrical engine and the radical change of replacing everything that mechanically wears out can include also electric wear due to multistressed loads and not just a list of improvements. The EM design based study on specifying EM for LPS 1) caused concern on machine size due to large inner diameter in respect to speed range and magnetizing frequency that causes unnecessary high core losses and low efficiency at desirable operation range which cannot be replaces simply by more efficient materials or technologies, 2) performance and power density need to be compromised to the improvement in faultless design: for high speed rotor and matched specification for EM winding layout, EIS and PEC topology, 3) cooling integration may provide solutions but that with new challenges.

\section{Acknowledgement}

The author would like to thank for the collaborative working atmosphere between GKN, LTH, KTH and Chalmers in VIND project that is supported by VINNOVA-NFFP7 program.

\section{References}

[1] R. R. Secunde, R. P. Macosko, D. S. Repas, "Integrated engine-generator concept for aircraft electric secondary power", Nasa technical memorandum x-2579, 1972.

[2] M. J. Provost, "The More Electric Aero-engine: a general overview from an engine manufacturer", 2002 International Conference on Power Electronics, Machines and Drives (Conf. Publ. No. 487), June 2002, pp.246-251

[3] J. A. Weimer, "The role of electric machines and drives in the more electric aircraft", IEEE International Electric Machines and Drives Conference, 2003. IEMDC'03., June 2003, pp.11-15 vol.1

[4] C. R. Avery, S. G. Burrow, P. H. Mellor, "Electrical generation and distribution for the more electric 
aircraft", 2007 42nd International Universities Power Engineering Conference, Sep. 2007, pp.1007-1012

[5] B. Sarlioglu, C. T. Morris, "More Electric Aircraft: Review, Challenges, and Opportunities for Commercial Transport Aircraft", IEEE Transactions on Transportation Electrification, V 1 n 1, June 2015, pp.54-64

[6] V. Madonna, P. Giangrande, M. Galea, "Electrical Power Generation in Aircraft: Review, Challenges, and Opportunities", IEEE Transactions on Transportation Electrification, V 4 n 3, Sep. 2018, pp.646-659

[7] M. Henke, G.Narjes, J. Hoffmann, C. Wohlers, S. Urbanek, C. Heister, J. Steinbrink, W.-R. Canders, B. Ponick, "Challenges and Opportunities of Very Light High-Performance Electric Drives for Aviation", Energies 2018, 11, 344

[8] Pratt\&Whitney GTF-Engine https://www.pw.utc.com /products-and-services/products/commercialengines/pratt-and-whitney-gtf

[9] B. Rahrovi, M. Ehsani, "A Review of the More Electric Aircraft Power Electronics", 2019 IEEE Texas Power and Energy Conference (TPEC), Feb 2019, pp.1-6

[10] G. L. Calzo, P. Zanchetta, C. Gerada, A. Gaeta, F. Crescimbini, "Converter topologies comparison for more electric aircrafts high speed Starter/Generator application", 2015 IEEE Energy Conversion Congress and Exposition (ECCE), Sep. 2015, pp.3659-3666

[11] G. Buticchi, S. Bozhko, M. Liserre, P. Wheeler, K. Al-Haddad, "On-Board Microgrids for the More Electric Aircraft-Technology Review", IEEE Transactions on Industrial Electronics, V 66 n 7, July 2019, pp.5588-5599

[12] V. Yaramasu, B. Wu, P. C. Sen, S. Kouro, M. Narimani, "High-power wind energy conversion systems: State-of-the-art and emerging technologies", Proceedings of the IEEE, V 103 n 5, May 2015, pp.740-788

[13] D. Kumar, F. Zare, A. Ghosh, "DC Microgrid Technology: System Architectures, AC Grid Interfaces, Grounding Schemes, Power Quality, Communication Networks, Applications, and Standardizations Aspects", IEEE Access, V $5 \mathrm{n}$, 2017, pp.12230-12256

[14] C. Gammeter. F. Krismer, J. W. Kolar, "Weight and efficiency analysis of switched circuit topologies for modular power electronics in MEA", IECON 2016 42nd Annual Conference of the IEEE Industrial Electronics Society, Oct 2016, pp.3640-3647
[15] W. Cao, B. C. Mecrow, G. J. Atkinson, J. W. Bennett, D. J. Atkinson, "Overview of Electric Motor Technologies Used for More Electric Aircraft (MEA)", IEEE Transactions on Industrial Electronics, V 59 n 9, Sep. 2012, pp.3523-3531

[16] Z. Zhang, J. Huang, Y. Jiang, W. Geng, Y. Xu, "Overview and analysis of PM starter/generator for aircraft electrical power systems", CES Transactions on Electrical Machines and Systems, V 1 n 2, 2017, pp.117-131

[17] R. Bojoi, A. Cavagnino, A. Tenconi, A. Tessarolo, S. Vaschetto, "Multiphase electrical machines and drives in the transportation electrification", 2015 IEEE 1st International Forum on Research and Technologies for Society and Industry Leveraging a better tomorrow (RTSI), Sep. 2015, pp.205-212

[18] P. Arumugam, D. Barater, T. Hamiti, C. Gerada, "Winding concepts for ultra reliable electrical machines", IECON 2014 - 40th Annual Conference of the IEEE Industrial Electronics Society, Oct 2014, pp.959-964

[19] D. Barater, F. Immovilli, A. Soldati, G. Buticchi and G. Franceschini, C. Gerada, M. Galea, "Multistress Characterization of Fault Mechanisms in Aerospace Electric Actuators", IEEE Transactions on Industry Applications, V 53 n 2, March 2017, pp.1106-1115

[20] K. Rajashekara, "Parallel between More Electric Aircraft and Electric-Hybrid Vehicle Power Conversion Technologies", IEEE Electrification Magazine, V 2 n 2, June 2014, pp.50-60

[21] M. van der Geest, H. Polinder, J. A. Ferreira, D. Zeilstra, "Machine selection and initial design of an aerospace starter/generator", 2013 International Electric Machines Drives Conference, May 2013, pp.196-203

[22] D. Gerada, A. Mebarki, N. L. Brown, C. Gerada, A. Cavagnino, A. Boglietti, "High-Speed Electrical Machines: Technologies, Trends, and Developments", IEEE Transactions on Industrial Electronics, V $61 \mathrm{n}$ 6, June 2014, pp.2946-2959

[23] Ma Xiaohe, Su Rong, Tseng King Jet, Wang Shuai, Zhang Xiaolong, V. Vaiyapuri, G. Chandana, G. Amit, N. Sivakumar, "Review of high speed electrical machines in gas turbine electrical power generation", TENCON 2015 - 2015 IEEE Region 10 Conference, Nov 2015, pp.1-9

[24] H. Lahne, D. Gerling, "Comparison of state-of-the-art high-speed high-power machines: Research study including a design example of a $50000 \mathrm{rpm}$ induction machine", IECON 2015 - 41st Annual Conference of 
the IEEE Industrial Electronics Society, Nov 2015, pp.003519-003524

[25] M. van der Geest, H. Polinder, J. A. Ferreira, M. Christmann, "Power Density Limits and Design Trends of High-Speed Permanent Magnet Synchronous Machines", IEEE Transactions on Transportation Electrification, V 1 n 3, Oct 2015, pp.266-276

[26] A. Binder, W.-R. Canders, "Tutorial High Speed Drives”, Int. Conf. on Electrical Machines, 2014

[27] R. Benlamine, T. Hamiti, F. Vangraefschepe. D. Lhotellier, "Electromagnetic, Structural and Thermal Analyses of High-Speed PM Machines for Aircraft Application", 2018 XIII International Conference on Electrical Machines (ICEM), Sep. 2018, pp.212-217

[28] A. Yu, G. W. Jewell, "Systematic design study into the influence of rotational speed on the torque density of surface-mounted permanent magnet machines", The Journal of Engineering, V 2019 n 17, 2019, pp. $4595-4600$

[29] E. Richter, C. Ferreira, "Performance evaluation of a $250 \mathrm{~kW}$ switched reluctance starter generator", Proc. Conf. Rec. IEEE 13th IAS Annu. Meeting Ind. Appl. Conf. (IAS), vol. 1, pp. 434-440, Oct. 1995.

[30] A. V. Radun and C. A. Ferreira and E. Richter, "Twochannel switched reluctance starter/generator results", IEEE Transactions on Industry Applications, V $34 \mathrm{n}$ 5, Sep. 1998, pp.1026-1034

[31] A. J. Mitcham, N. Grum, "An integrated LP shaft generator for the more electric aircraft", IEE Colloquium on All Electric Aircraft (Digest No. 1998/260), June 1998, pp.8/1-8/9

[32] Z. Sun, J. Ede, J. Wang, G. Jewell, J. Cullen, A. Mitcham, "Experimental testing of a $250-\mathrm{kW}$ faulttolerant permanent magnet power generation system for large civil aero engines", Proc. 5th Int. Conf. Energy Conversion Engineering (IECEC), pp. 1-8, 2007-June.

[33] P. Arumugam, Z. Xu, A. La Rocca, G. Vakil, M. Dickinson, E. Amankwah, T. Hamiti, S. Bozhko, C. Gerada, S. J. Pickering, "High-Speed Solid Rotor Permanent Magnet Machines: Concept and Design", IEEE Transactions on Transportation Electrification, V 2 n 3, Sep. 2016, pp.391-400

[34] A. L. Rocca, Z. Xu, P. Arumugam, S. J. Pickering, C. N. Eastwick, C. Gerada, S. Bozhko, "Thermal management of a high speed permanent magnet machine for an aeroengine", 2016 XXII International Conference on Electrical Machines (ICEM), Sep. 2016, pp.2732-2737
[35] A. Diab, M. Rashed, J. Li, C. Gerada, S. Bozhko, "Performance Analysis of PMSM for High-Speed Starter-Generator System", 2018 IEEE International Conference on Electrical Systems for Aircraft, Railway, Ship Propulsion and Road Vehicles International Transportation Electrification Conference (ESARS-ITEC), Nov 2018, pp.1-7

[36] F. R. Ismagilov, V. E. Vavilov, D. V. Gusakov, "High-Speed Starter-Generator for Aerospace Applications: Design and Initial Testing", 2018 XIII International Conference on Electrical Machines (ICEM), Sep. 2018, pp.2593-2599

[37] F. R. Ismagilov, V. E. Vavilov, D. V. Gusakov, "Design Features of Liquid-Cooled Aviation Starter Generators", 2018 IEEE International Conference on Electrical Systems for Aircraft, Railway, Ship Propulsion and Road Vehicles International Transportation Electrification Conference (ESARSITEC), Nov 2018, pp.1-5

[38] A. Balachandran, M. Boden, Z. Sun, S. J. Forrest, J. D. Ede, G. W. Jewell, "Design, construction, and testing of an aero-engine starter-generator for the more-electric aircraft", The Journal of Engineering, V 2019 n 17, 2019, pp.3474-3478

[39] A. Cavagnino, Z. Li, A. Tenconi, S. Vaschetto, "Integrated Generator for More Electric Engine: Design and Testing of a Scaled-Size Prototype", IEEE Transactions on Industry Applications, V 49 n 5, Sept 2013, pp.2034-2043

[40] R. Bojoi, A. Cavagnino, A. Tenconi, S. Vaschetto, "Multiphase PM machine for More Electric Aircraft applications: Prototype for design validation", IECON 2012 - 38th Annual Conference on IEEE Industrial Electronics Society, Oct 2012, pp.3628-3634

[41] N. Fernando, G. Vakil, P. Arumugam, E. Amankwah, C. Gerada, S. Bozhko, "Impact of Soft Magnetic Material on Design of High-Speed Permanent-Magnet Machines", IEEE Transactions on Industrial Electronics, V 64 n 3, March 2017, pp.2415-2423

[42] A. Reinap, "Aerospace electric generator design considerations" Electric drives production conference, EDPC 2019

[43] "Soft magnetic cobalt-iron alloys", Vacuumschmelze (available online)

[44] "Lamination Stacks made of VACOFLUX X1", Vacuumschmelze (available online)

[45] "Energy Savings with Thin Gauge for Motors, Generators, Transformers and Inductors", Arnold Magnetic Technologies, (available online) 
[46] "Arnon thin and ultra-thin silicon iron datasheet", Arnold Magnetic Technologies, (available online)

[47] A. Reinap, M. Andersson, F.J. Márquez-Fernández, P. Abrahamsson, M.Alaküla, "Performance Estimation of a Traction Machine with Direct Cooled Hairpin Winding". IEEE Transportation Electrification Conference and Expo (ITEC), Novi, MI, USA, 19-21 June 2019. pp. 1-6. 